\title{
USO DE ALGORITMOS DE INTELIGÊNCIA ARTIFICIAL NA GESTÃO DE REDES SOCIAIS E O SEU IMPACTO NOS PROCESSOS DE DIFUSÃO DO CONHECIMENTO
}

\begin{abstract}
Resumo: Entrevista realizada pela Revista PontodeAcesso ao professor Reinaldo de Figueiredo Almeida, atuando nas áreas de Sistemas de Informações e de Administração, e de Analista de Telemática da Empresa de Tecnologia e Informações da Previdência Social (Dataprev), atuando em projetos de Qualificação de Dados e Inteligência de Negócios. Faz uma exposição sobre o uso de algoritmos de inteligência artificial na gestão de redes sociais e o seu impacto nos processos de difusão do conhecimento, e como a atuação destes algoritmos impacta na difusão do conhecimento quando se tem as redes sociais como suporte. Isto acontece porque os algoritmos sempre exercem um propósito que está ligado aos interesses daqueles que detêm poder, ou sobre os meios de comunicação ou sobre a propriedade das redes sociais. Na entrevista, é esclarecido como a ação dos destes algoritmos influencia no comportamento dos perfis dos usuários e como isto determina a forma como o conhecimento é difundido. Isto leva a introdução de uma hipótese, segundo a qual, todos os seres humanos que passam a interagir com o mundo digital, e em última instância, com o universo das redes sociais, passa a dispor de duas existências: uma analógica, aquela relacionada ao seu ambiente físico, e uma digital, aquela relacionada aos conjuntos de dados que foram acumulados a partir das interações com o mundo digital.
\end{abstract}

Palavras-chave: Algoritmos. Inteligência artificial. Redes Sociais. Difusão do Conhecimento.

\section{ARTIFICIAL INTELLIGENCE ALGORITHMS USE IN THE MANAGEMENT OF SOCIAL MEDIAS AND THEIR IMPACT ON KNOWLEDGE DIFFUSION PROCESSES}

\begin{abstract}
Interview conducted by the magazine PontodeAcesso to Professor Reinaldo de Figueiredo Almedia, working in the areas of Information Systems and Administration, and Telematics Analyst at the Empresa de Tecnologia e Informações da Previdência Social (Dataprev), working on Data Qualification and Business Intelligence projects. He makes an exhibition about the use of artificial intelligence algorithms in the management of social networks and their impact on the processes of knowledge difusion, and how the performance of these algorithms impacts on the knowledge difusion when social networks are supported. This is because the algorithms always exert a purpose that is linked to the interests of those who hold power, or on the media or on the ownership of social networks. In the interview, it is clarified how the action of these algorithms influences the behavior of the users' profiles and how this determines how the knowledge is difusion. This leads to the introduction of a hypothesis, according to which, all human beings that start to interact with the digital world, and ultimately, with the universe of social networks, have two existences: an analog, one related to the its physical environment, and a digital one, that related to the data sets that were accumulated from the interactions with the digital world.
\end{abstract}

Keywords: Algorithms. Artificial intelligence. Social media. Knowledge difusion. 


\section{Entrevista}

Revista PontodeAcesso: Poderíamos iniciar por entender o que são as redes sociais?

Prof. Reinaldo Almeida: Perfeito. O conceito de redes sociais vem da Antropologia e da Sociologia e foi apropriado pela área de Computação para caracterizar comunidades no mundo digital, onde pessoas se conectam entre si a partir da mediação de computadores. Esta definição consta num artigo fundamental sobre o tema, Computer Networks as Social Networks [1], publicado em 1996 por pesquisadores do Centre for Urban and Community Studies da Universidade de Toronto no Canadá.

Nele, estas redes sociais no ambiente digital são chamadas de CSSN (ComputerSupported Social Network) e são caracterizadas como espaços que facilitam o trabalho colaborativo e favorecem mais a desinibição, a criatividade e a contundência do que a comunicação direta entre pessoas, sustentando tanto laços fortes, como laços intermediários e fracos.

Mas um ponto no artigo que considero importante é aquele ressalta que as CSSN (ou simplesmente redes sociais) tanto restringem como facilitam o controle social. Isto ocorre porque estas operam sobre um ambiente controlado, por quem detêm o poder sobre os meios de comunicação de dados (governos, empresas) e por quem tem a propriedade sobre as redes sociais (empresas). Em outras palavras, toda a comunicação ocorrida sobre uma rede social num ambiente digital, independente da relação exercida entre os nós da rede (formada por emissores e receptores de mensagens), atendem a uma série de regras de conformidade e de propósitos.

Revista PontodeAcesso: E quem gere a atenção a estas regras de conformidade e aos propósitos numa rede social digital ou CSSN?

Prof. Reinaldo Almeida: Na imensa maioria das vezes, isto será executado por algoritmos de IA (Inteligência Artificial) de forma autônoma. Digo na maioria das vezes porque, eventualmente, a ocorre a intervenção humana, como ocorreu quando houve a exclusão da conta do ex-presidente Donald Trump da rede Twitter. 
Estes algoritmos são muito sofisticados e estão em treinamento permanente, a fim de evitar as violações das regras que todos, antes de se cadastrar numa rede social digital, aceitam. Mas não apenas para isto! O principal objetivo do treinamento que os algoritmos praticam, está orientado para garantir que os propósitos das redes sejam alcançados, a partir da ação dos seus membros, dentro da rede e, eventualmente, fora dela. Neste ponto, é importante aclarar que uma CSSN ou rede social digital é um projeto industrial e comercial (e aí incluo as 4 grandes redes sociais do momento: Instagran, Youtube, Facebook e Twitter [2]) e como tal, necessita se monetizar para se manter em funcionamento, e é para atender a este ponto que os algoritmos de IA atuam, arbitrando a troca de mensagens e sugerindo novas conexões e o consumo de determinado conteúdo.

Sobre a atuação dos algoritmos de IA na gestão das redes recomendo 2 trabalhos: o documentário na NETFLIX, O Dilema das Redes, e o livroThe Hidden Psychology of Social Networks [3], escrito por Joe Federer, ex-líder de estratégia de uma das maiores redes sociais dos Estados Unidos, a Reddit. No primeiro, há o testemunho de vários ex-executivos das principais redes sociais sediadas nos EUA, explicando como estes algoritmos atuam. Destaco as citações referentes ao Behavior Design Labda universidade americana de Stanford, especializado em tecnologia persuasiva e onde estudou a maioria dos executivos que testemunham no documentário. Este laboratório se tornou referência mundial no desenvolvimento de tecnologias persuasivas, principalmente, na elaboração de estratégias para design de interfaces e de interações e na elaboração de modelos matemáticos para aplicação em algoritmos de IA, a fim de gerar identificação de padrões de comportamentos e predições sobre comportamentos futuros.

Em relação ao livro de Federer, cabe ressaltar que ele é constituído de extensivo e detalhado texto baseado em múltiplas disciplinas, tais como, biologia evolutiva, antropologia, neuroanatomia e psicologia. Nele, destaco uma das suas conclusões, segundo a qual, para nossos cérebros as redes sociais são reconhecidas como espaços reais onde nos movimentamos dentro delas e não sobre elas, principalmente, pelo fato de construirmos e mantermos projeções de "eu" representados nestas redes. Aqui, a ideia de projetar o "eu" deve ser compreendida como a análise efetuada pelos algoritmos de uma rede social sobre os dados gerados e mantidos sobre um determinado perfil digital de um indivíduo, aos quais eles possuem acesso.

Para ilustrar esta conclusão apresentada por Federer, temos a experiência da 
jornalista francesa, Judith Duportail, que transformou a sua experiência com a rede social Tinder no livro, L’Amour sous algorithme [4]. Nele, Duportail conta que depois de desconfiar que a Tinder estava lhe sugerindo certos perfis para contatos que se alinhavam com o momento pessoal que estava passando, resolveu apelar para a GPDR (General Data Protection Regulation), lei que regulamenta a proteção de dados na União Europeia, e conseguiu obter mais de 800 páginas com dados sobre o seu perfil, fornecidas pelo Tinder. No livro, Duportail, apresenta várias análises efetuadas sobre os dados apresentados, onde foi possível reconstruir, por exemplo, sua trajetória emocional durante 1 ano (tempo em que esteve na rede).

Neste ponto devo insistir, que a ação dos algoritmos ocorre sempre sobre a infinidades de dados que fornecemos ao mundo digital, de forma direta e indireta, aos quais eles têm acesso. Então, quando falamos de perfil de um indivíduo neste universo, estamos falando do perfil de um indivíduo que foi formado por algoritmos com bases nos dados relativos ao mesmo que se encontravam disponíveis.

Revista PontodeAcesso: Então, o nosso perfil na rede seria na verdade um avatar? Não seria nós mesmos?

Prof. Reinaldo Almeida: Eu lhe respondo com base em uma hipótese que venho formulando para explicar este fenômeno. O cenário atual, após as 2 décadas iniciais do século XXI, aponta para a existência, por assim dizer, de 2 experiências existenciais para a maioria dos indivíduos que habitam sociedades modernas: uma experiência existencial analógica e outra, digital.

Isto é muito significativo uma vez que, enquanto se estima que as primeiras sociedades humanas analógicas datam de $8.000 \mathrm{AC}$, de acordo com as pesquisas de John Lubbock [11], as sociedades humanas digitais apoiadas sobre a internet e, mais recentemente, sobre as redes sociais, remontam a 1983 quando o protocolo de comunicação usado pela grande rede mundial de computadores passou a ser o TCP/IP [11], permitindo uma explosão do seu uso para além dos ambientes militar e acadêmico. Isto é extremamente crítico, porque significa que um mesmo indivíduo carrega consigo 2 experiências baseadas em processos existenciais muito distintos, um maduro e outro, bastante imaturo, considerando uma escala temporal. 
Dito isto, minha hipótese é que esta diferença entre existências, analógica e digital, deverá ser observada sempre que se pretenda fazer análises envolvendo elementos dos 2 cotidianos. Por exemplo, o princípio da casualidade determina que um evento passado antecede um evento presente que antecede um que ocorrerá no futuro, e que nos levaria a inferir pela existência de um passado imutável, um presente mutável e um futuro a se definir [12]. Ao tratarmos este princípio sob a perspectiva de uma experiência digital, tem-se que este não se determina, uma vez que um evento presente pode alterar um evento passado como pode predizer um evento futuro.

Tomando-se o exemplo anterior, poderíamos perguntar: como ficaria a análise do perfil de um indivíduo, tendo como base suas experiências analógicas e digitais? Na minha hipótese, com base em suas experiências analógicas, diria que o indivíduo tem o seu perfil analisado sobre 2 perspectivas: uma relativa ao passado, baseada em registros gerados desde seu nascimento, atestando sua origem e filiação, por exemplo, e outra relativa ao seu presente, com base na observação direta de suas ações. Numa perspectiva digital, o indivíduo tem seu perfil analisado a partir de 1 única perspectiva: o presente, formado pela combinação dos seus registros no passado, no presente e naqueles preditos para o futuro.

Deste modo, quero enfatizar que há diferenças entre as 2 experiências existências, e ao se analisar experiências cometidas pelos indivíduos, faz-se necessário situar sobre quais existências estas foram vividas. Isto pode ser percebido, por exemplo, pelas ações de diversos países ao criarem legislações, normativas ou não, próprias ao mundo digital, a fim de poderem arbitrar sobre eventos ocorridos no mesmo. Posso citar no Brasil recente 2 novas leis promulgadas com esta finalidade, o Marco Civil da Internet (Lei n.12.965, de 23 de abril de 2014) e a Lei Geral de Proteção de Dados ou LGPD (Lei n⿳ 13.709, de 14 de agosto de 2018).

Revista PontodeAcesso: Considerando a resposta do senhor, acho que seria importante falarmos como é gerada e mantida esta existência digital, antes de nos concentrar nas questões da difusão do conhecimento no contexto das redes sociais?

Prof. Reinaldo Almeida: Perfeito. Para falar da construção de uma experiência existencial digital de um indivíduo, o melhor a fazermos é trazer alguns dados que refletem o quanto ela se faz presente e o quanto tende a se intensificar nos próximos anos. 
Segundo o relatório Digital in 2020 [13] produzido pelo blog We Are Social, mantido pela HootSuite, uma das principais empresas na gestão de marcas no mundo digital e conhecida por gerar estatísticas relativas a este mundo, em 2020, a quantidade de pessoas que usaram a internet cresceu 7\% em relação à 2019 e alcançou a cifra de 4,54 bilhões de pessoas das quais, 3,8 bilhões, são usuárias de pelo menos 1 rede social. Em outras palavras, considerando que no mesmo período a população mundial chegou aos 7,75 bilhões de seres humanos, aproximadamente $59 \%$ da população global passa parte de seu tempo atuando no mundo digital.

Em relação, especificamente às redes sociais, as 3,8 bilhões de pessoas que as usam geraram em 2019, segundo o serviço Facebook Analytics [14], mais de 700 milhões de acessos mensais na rede social Facebook, envolvendo o armazenamento e análise de mais de 50 petabytes (50x10 $10^{15}$ bytes) de dados. De igual modo, segundo o Twitter Analytics [15], em 2019, foram enviados pela rede social Twitter,diariamente, mais de 500 milhões de mensagens, com uma média de 5.700 TPS (twittes per second ou mensagens por segundo). Por fim, de acordo com o Google Transparency Report [16], o "motor" de pesquisa daGoogle rastreia, em média, 20 bilhões de sítios da internet, diariamente, armazenando 100 petabytes $\left(100 \times 10^{15}\right.$ bytes $)$ de dados.

Numa outra visão, tem-se que, segundo a OMC (Organização Mundial do Comércio) [17], em 2019 o comércio eletrônico (e-commerce) movimentou 3,306 trilhões de dólares, estimando-se um crescimento de 18,4\% (algo como 3,914 trilhões de dólares) e representando 14,8\% do comércio global. De acordo com a mesma fonte, o comércio mundial como um todo cresceu 4,5\% de 2018 para 2019, mas deverá ter índice negativo de 9,2\% de 2019 para 2020, o que demonstra o quanto as experiências digitais tendem a ser relevantes no dia a dia das pessoas, em relação ao segmento de comércio.

Nos próximos anos, prevê-se que esta realidade se intensificará, aumentando ainda mais as vivências baseadas em experiências digitais. Para tanto, isto deverá ocorrer, seja pela nova realidade imposta pelo vírus SARS-COVID-19 e pela possibilidade de novas pandemias, seja pela evolução de algumas tecnologias consideradas altamente estruturantes, como as tecnologias: 5G para comunicação de dados e a Internet das Coisas ou IoT (Internet of Things), responsável por prover a capacidade para que os objetos possam estabelecer comunicação entre si, independente da intervenção humana.

Com estas 2 tecnologias combinadas, o que veremos é o aumento daquilo que já 
vivemos em uma escala significativa nos dias atuais: nossos celulares "conversando" com as antenas de repetição de sinais espalhadas pelo trajeto da nossa caminhada diária, gerando registros sobre os nossos movimentos, ou nossos carros ao se deslocarem em uma velocidade não permitida, tendo a imagem de sua placa capturada por um radar de trânsito e enviada para um computador central, o qual nos identificará, registrará o nosso evento de infração às leis de trânsito e nos encaminhará um aviso de infração cometida.

A partir da implantação da comunicação $5 \mathrm{G}$ e a popularização da IoT, os exemplos citados se intensificarão ainda mais, com as nossas geladeiras comunicando aos supermercados nossas necessidades ou com nossos carros conversando com outros carros e com autoridades policiais, registrando os eventos gerados por nossas ações.

Assim, para cada registro efetuado nos ambientes digitais relativos as ações dos indivíduos junto a estes, de modo direto ou indireto (através dos objetos com os quais temos algum tipo de relação), ocorrerá o que trago em minha hipótese como a geração de uma cópia do nosso "eu" para uma nova existência, agora digital, fazendo com que um indivíduo passe a ser reconhecido na sociedade a partir de dois perfis existenciais, um analógico e um digital.

Parece confuso, mas esta já é nossa realidade. De novo vamos aos dados, segundo o último relatório produzido pela consultoria mundial Deloitte relacionada a capital humano [18], 28\% dos recrutamentos de pessoal no mundo já ocorrem a partir de pesquisas nas redes sociais. Ora, estas pesquisas não recrutam perfis baseados em experiências existenciais analógicas, mas naqueles baseados em experiências existenciais digitais, formados pelos milhares de registros de dados obtidos, de modo direto ou indireto, com base em eventos relativos a um indivíduo.

Deste modo, voltando a sua questão. Sim, temos uma projeção do nosso "eu" num espaço de experiência existencial digital, composto por uma infinidade de dados registradas neste espaço, a partir de ações que tomamos ao nos relacionar, direta ou indiretamente, com ele. E este movimento faz surgir para um mesmo indivíduo 2 experiências existenciais ou se preferi, 2 perfis, um analógico e outro digital.

Revista PontodeAcesso: E como ocorre a validação da acurácia deste perfil digital? Confrontando com o perfil analógico, como ocorre nas avaliações de prova de vida? 
Prof. Reinaldo Almeida: Não necessariamente. A Previdência Social brasileira, por exemplo, lançou, recentemente, o serviço para prova de vida dos seus beneficiários através de uma aplicação no celular, onde a imagem da pessoa é capturada em 2 momentos simultâneos: uma obtida diretamente do indivíduo e outra de uma documentação com foto (no caso, a Previdência recomenda o uso da Carteira Nacional de Habilitação). Estes dados seguem para registros digitais, e algoritmos especializadas fazem a confrontação das 2 imagens para confirmar se o indivíduo está vivo. A confirmação de que o indivíduo está vivo ocorre, portanto, a partir de sua experiência existencial digital, sem acessar o mundo analógico.

Atualmente, uma das tecnologias mais usadas para armazenar registros de dados é aquela conhecida por Big Data, definida como uma tecnologia capaz de oferecer uma abordagem consistente no tratamento do constante crescimento e da complexidade dos dados, e observando aspectos relativos ao volume, à velocidade, à variedade, à veracidade e ao valor destes [19].

Esta tecnologia é a mais usada, atualmente, para armazenar os dados gerados pelas redes sociais. A ideia é que o volume armazenado seja limitado apenas pela capacidade física existente dos servidores de dados e que, mesmo com um grande volume de dados gravados, seja possível acessá-los com uma velocidade aceitável, armazenando-os em todos os formatos conhecidos, e que os dados armazenados sejam capazes de gerar valor e sejam verazes. Aqui reside um ponto crucial, como confirmar a veracidade de todos os dados armazenados. Para tanto, a solução encontrada, na maioria absoluta das vezes, é delegar a algoritmos de IA esta tarefa, que farão isto ao analisar o universo de dados armazenados, num processo de perfeita circularidade. Isto é, o dado analisado dependerá do seu grau de qualidade e da existência e da qualidade de outros dados que poderiam ser usados na confirmação de sua veracidade.

Revista PontodeAcesso: Então, traçado todo este cenário, vamos a questão de como as redes sociais impactam no processo de difusão do conhecimento. Poderíamos dizer que esta questão tem que ser tratada em 2 planos, analógico e digital?

Prof. Reinaldo Almeida: Sim. Mas é importante incluir na pergunta a gestão das redes sociais por algoritmos de IA. Isto tem que ser enfatizado porque quando pensamos nas 
trocas que ocorrem entre indivíduos numa rede social, não temos apenas as figuras do emissor e receptor, há, também, a figura arbitral de uma IA que procura garantir a conformidade das trocas efetuadas e os interesses estabelecidos pelos stakeholders das redes, como falamos anteriormente.

Para responder a esta questão eu irei trazer alguns eventos ocorridos.

Eu estava dando uma palestra sobre uso tecnologias no ensino numa universidade em Lauro de Freitas, Bahia, e fui questionado por uma professora que estava na plateia sobre o uso cada vez maior de fontes alternativas de conhecimento pelos estudantes, como vídeos da rede social Youtube. Minha resposta foi que tais usos eram inevitáveis e minha sugestão era no sentido de que os professores passassem a considerar estas fontes como válidas, consumindo-as, e orientando aos alunos de como as consumir. No caso da Youtube, seria buscar vídeos importantes para o processo de difusão do conhecimento pretendido, e recomendá-los aos estudantes, juntamente com as estratégias de como fazer estas buscas.

Qual é o efeito prático disto? No momento que os estudantes passem a consumir determinados tipos de vídeos, a Youtube irá arbitrar e irá sugerir cada vez mais vídeos que possuam metadados com conteúdos similares àqueles que foram sugeridos. Com isto, não só o conhecimento esperado será difundido como o perfil da experiência existencial digital dos estudantes será alterada para indicar a preferência destes por este tipo de vídeos. Isto poderá ser determinante numa eventual seleção para emprego baseado na busca de perfis em redes sociais, por exemplo, além de aumentar a qualidade do conhecimento difundido a eles.

Neste ponto temos algumas questões. A primeira trata do quanto um perfil baseado na existência digital do indivíduo refletiria um perfil existencial analógico deste. Esta é uma questão crítica que expressa a dissociação dos 2 mundos. Possivelmente, esta seja a razão pela qual as empresas, em geral, usam IA em parte do seu processo de recrutamento, efetuando uma filtragem de possíveis candidatos, deixando para a avaliação humana a tarefa de confirmar os recrutados. Numa ação que as empresas julgam necessária para garantir a acurácia do perfil recrutado em relação ao perfil desejado.

Uma outra questão se refere à arbitragem efetuada pelos algoritmos de IA nas redes sociais. Quando a Youtube analisa o perfil de quem está demandando o vídeo, há um cruzamento entre as informações associadas ao vídeo e àquelas relacionadas ao perfil requisitante, neste momento, a rede constrói uma série de inferências sobre o indivíduo e fornece a este, além do vídeo solicitado, sugestões de outros vídeos relacionados àquele que 
foi fornecido.

Os algoritmos operaram desta forma, a fim de atender ao menos estes 3 propósitos: satisfazer ao requerente, confirmar as inferências relativas ao seu perfil com base nos outros vídeos sugeridos e, o mais importante, encaminhar publicidades de empresas que tenham sua imagem (obtida por suas ações institucionais ou por seus produtos e serviços fornecidos) alinhadas com características do perfil digital do requerente. Isto está bem descrito num artigo publicado em 2016 no Journal of Business Research, por pesquisadores do Instituto CAPHRI (Care and Public Health Research Institute) da Universidade de Maastricht nos Países Baixos [20].

Este artigo trata do uso do assim chamado marketing viral, ou comumente chamado de marketing boca a boca, através de redes sociais. Nele foram analisados aspectos da vivência em redes sociais e como isto é explorado pelas empresas para aplicar marketing boca a boca com sucesso. O foco principal foi identificar preditores do comportamento real dos indivíduos quando estes tornam viral uma campanha publicitária no contexto das redes sociais, e a conclusão foi de que a imagem positiva de uma empresa é o mais significativo dos preditores. Isto é, quanto mais eu promovo a publicidade de uma empresa junto a perfis alinhados com as características desta, mas eu reforço a sua imagem positiva e possibilito a identificação de novos perfis alinhados com a empresa. Assim, aumenta-se a possibilidade de tornar viral uma peça publicitária.

Outro evento que podemos usar para responder à questão colocada, diz respeito a uma notícia publicada recentemente na BBC Brasil [21]. O título era Epidemiologista que alertava contra COVID-19 perde pai que "preferia acreditar no Whastapp". Na reportagem a epidemiologista cita a raiva e a frustação por não ter conseguido convencer ao pai sobre os riscos causados pelo vírus, SARS COVID-19, e declarou que "As desinformações nas redes deturpavam todas as medidas que eu falava para o meu pai adotar. Não dá para competir (com fake news). As pessoas acreditam naquilo que querem.Essa confusão de comunicação de risco que temos no Brasil matou o meu pai". Nesta declaração há alguns pontos a observar.

Começo por As desinformações nas redes deturpavam todas as medidas que eu falava para o meu pai adotar. Uma desinformação ou informação inverídica ou incompleta gera ruídos no processo de difusão do conhecimento, deturpando-o. O ponto a ser observado é porque uma informação que gera ruídos prospera?O processo de checagem da veracidade 
dos dados que circulam nas redes falhou? A resposta imediata seria sim, falhou, mas a situação é mais complexa. Para checar a veracidade de um dado é necessário acessar ao histórico deste dado e a outros conjuntos de dados relacionados a este, como os volumes são imensos e sempre haverá um limite à capacidade de armazenamento e de processamento, a lógica atribuída aos algoritmos responsáveis pela arbitragem na rede obedece a uma hierarquia de prioridades (recordemos que uma rede social é um projeto industrial e, na maioria das vezes, comercial).

Sendo assim, uma informação continua veraz, enquanto o movimento de circularidade para checagem dos seus dados assim confirmar. Por isso, ela continuará sendo admitida na rede, em especial, entre aqueles que estão consumindo-a. Quando, em algum momento, outros dados acessados indicarem que ela não é consistente, ela começará a perder o grau de veracidade e isto poderá levar a sua exclusão, alterando a natureza dos conhecimentos difundidos que usam a mesma. Para acelerar este processo de checagem da veracidade dos dados, muitas redes têm oferecido aos seus membros a oportunidade de registrar sobre a natureza de uma informação que recebe. Isto agrega novos dados a serem observados pelos algoritmos, e poderá assim, evitar que informações não verazes prosperem, gerando conhecimentos que levem a tomadas de decisões equivocadas.

Num outro momento da fala da epidemiologista ela declara Não dá para competir (com fake news). As pessoas acreditam naquilo que querem. Uma rede social observa seus membros a partir do seu perfil digital e não do analógico. Toda vez que uma pessoa clica num botão de like (uma invenção considerada fundamental para a sobrevivência das redes sociais [22]) ou ela repassa uma mensagem recebida ou curte uma imagem ou um texto, ela está agregando dados ao seu perfil digital, e isto será usado toda a vez que ela fizer um movimento na rede. Por isto, trago a minha hipótese de se construir a análise sobre determinados temas, tendo em mente a existência de 1 indivíduo e 2 perfis (analógico e digital). Isto é importante, porque é comum ouvir comentários como "uma pessoa tão inteligente, mas repassa mensagens terríveis". Estamos falando de um indivíduo, mas com 2 perfis distintos!

Já falamos de como o perfil digital é construído, porém devemos atentar para o fato de que, a maturidade digital não tem relação com a maturidade analógica, também falamos disto. Uma pessoa pode ter um perfil bem formado e maduro no mundo analógico e ser uma analfabeta e imatura digital, vide o relatório The Inclusive Internet Index 2020 [23], 
produzido anualmente pela revista britânica The Economist com o patrocínio do Facebook. Nele, em 2020, entre 100 países o Brasil aparece na 44 posição quanto ao indicador relativo à alfabetização digital. Isto demonstra que o analfabetismo digital é uma realidade, e é um dos fatores que poderia alterar o perfil digital de um indivíduo, trazendo como consequência, o consumo de conhecimentos inconsistentes.

Revista PontodeAcesso: Não há isenção no processo de difusão do conhecimento em uma rede social?

Prof. Reinaldo Almeida: Não é correto pensar nestes termos. Eu diria que a difusão do conhecimento em uma rede social estará sempre condicionada, na maioria das vezes, ao interesse demonstrado pela análise do perfil digital de um indivíduo. O que configura uma novidade. Melhor, a novidade é que estamos falando do perfil digital de um indivíduo, e não do seu perfil analógico.

É certo que cada rede social desenvolve suas estratégias para fidelizar e aumentar a quantidade de membros, assim como para aumentar o tempo que seus membros permanecem conectados. No seu livro, Federer procura demonstrar, baseado no modelo freudiano de Id, Ego e Superego para a psiquê humana, como a internet é um reflexo digital da psique humana coletiva e como diferentes redes sociais priorizam diferentes mentalidades: plataformas como aReddit para o Id não filtrado, a Facebook e a Twitter para o Ego gerenciado e aInstagram para o Superego ideal.

Como curiosidade, em minha tese de doutorado [24] trago a experiência da Microsoft com o bot Tay. A proposta da empresa foi criar um chatbot (sistema virtual capaz de gerar conversas que simulam a linguagem humana), projetado para responder perguntas e entabular conversas na rede social Twitter numa tentativa de capturar o mercado dos millenials (jovens entre 18 e 24 anos)nos Estados Unidos. Porém, o plano da empresa fracassou em poucas horas de operação, porque Tay não foi capaz de lidar com insultos, piadas e comentários racistas, sexistas, xenófobos, e relativos a teorias conspiratórias, como aquelas relacionadas aos atentados de 11 de setembro, e começou a reverberar mensagens de teor similar. A Microsoft retirou o Tay da rede e lamentou o ocorrido, em menos de 24 horas depois que o bot havia se cadastrado.

Um dos aspectos interessantes deste experimento, podemos chamar assim, foi de 
como o ambiente é determinante para a construção de um perfil de um indivíduo, inclusive no ambiente digital. Como os algoritmos estão sempre construindo inferências sobre um perfil, baseado nos seus dados e naqueles outros relacionados, a resultante é que a natureza do conhecimento que irá circular estará concentrada em determinado tipo ou padrão, até que o conteúdo dos dados envolvidos vá se alterando. Isto é uma das hipóteses para o cenário de polarização e de ressurgimento com força de teorias superadas ou sem fundamentação, que tem circulado nas redes, conforme argumenta o artigo Digital Hatred, Real Violence: Majoritarian Radicalisation and Social Media in India [25], do professor Mirchandani do Observer Research Foudation, na Índia. De acordo com o artigo, os movimentos de repulsa (ódio) e de atração (afeto) demonstrados pelos membros de uma rede social em relação a um tema, atuam em igual sentido para construção do processo de radicalização que nascem nas redes e transbordam para as ruas. Isto se dá, porque os algoritmos que arbitram os conteúdos nas redes terminam por influenciar o sucesso de umas narrativas em detrimentos de outras.

Há ainda um ponto que não explorei, que é o sentido de comunidade. A professora baiana, Dra. Edméa Santos da UFFRJ (Universidade Federal Rural do Rio de Janeiro), diz que "Não há interatividade no ambiente virtual se os sujeitos da comunicação não se autorizarem" [26]. Com base nisto, pode-se afirmar que uma rede social digital é formada por nós que se conectam, e estes nós são formados por perfis digitais de indivíduos que se autorizam mutuamente. Na perspectiva dos dados, isto quer dizer que dado 2 perfis, A e B, quando eles se conectam, o conjunto de dados de B será agregado ao conjunto de dados de A, e vice-versa. Deste modo, quando os algoritmos de IA que atuam na gestão da rede estiverem gerando inferências sobre A, eles usarão, também, os dados de B neste processo, sendo o inverso verdadeiro.

Portanto, podemos concluir, que no universo das redes sociais, o fluxo da difusão do conhecimento obedece, de modo prioritário, o espaço comunitário formado em torno de cada perfil, determinando assim, a natureza do conhecimento consumido e a amplitude de sua difusão.

Revista PontodeAcesso: Obrigado, professor.

Prof. Reinaldo Almeida: Eu que agradeço a oportunidade. 


\section{REFERÊNCIAS}

[1] WELLMAN, Barry, at al. COMPUTER NETWORKS AS SOCIAL NETWORKS: Collaborative Work,Telework, and Virtual Community. Annu. Rev. Sociol. n. 22, p. 213 238, 1996.

[2] spark.adobe.com/make/learn/top-social-media-sites.

[3] FEDERER, Joe. The Hidden Psychology of Social Networks: How Brands Create Authentic Engagement by Understanding What Motivates Us. $1^{\text {a }}$ edição. Nova York: Editora McGraw-Hill Education, 2020.

[4] DUPORTAIL, Judith.L'Amour sous algorithme. Paris: EditoraGoutte d'or: 2019.

[10] COTRIM, Gilberto. História Global: Brasil e geral. São Paulo: Editora Saraiva, 2005.

[11] MARTEL, Frédéric. SMART: O que você não sabe sobre a internet. Tradução: Clóvis Marques. $1^{a}$ edição. Rio de Janeiro: Editora Civilização Brasileira, 2015.

[12] REALE, Giovanni; ANTISERI, Dario. História da filosofia, v.1. Tradução: Ivo Storniolo. $2^{\text {a }}$ edição. São Paulo:Editora Paulus, 2004.

[13] wearesocial.com/digital-2020.

[14] analytics.facebook.com.

[15] analytics.twitter.com.

[16] transparencyreport.google.com.

[17] omcltd.in/About-Us/Financial-Performance-of-OMC/Audited-Annual-Reports.

[18] Deloitte. The social enterprise at work: Paradox as a path forward. 2020 Deloitte Global Human Capital Trends: 2020.

[19] www.gta.ufrj.br/grad/15_1/bigdata/vs.html.

[20] KETELAAR, Paul E.; et all. The success of viral ads: Social and attitudinal predictors of consumer pass-on behavior on social network sites. Journal of Business Research 69 2603-2613: 2016.

[21] www.bbc.com/portuguese/geral-55731179. 
[22] LANIER, Bruno. Dez argumentos para você deletar agora suas redes sociais). Trad.: Bruno Casotti. $1^{a}$ edição. São Paulo: Editora Intrínseca, 2018.

[23] theinclusiveinternet.eiu.com/explore/countries/performance?category=readiness.

[24] ALMEIDA. Reinaldo de Figueirêdo. ANÁLISE DE DOMÍNIO NA AQUISIÇÃO DE CONHECIMENTOS:Ontologias Para Sistemas Computacionais. Tese (Doutorado) Faculdade de Educação, Universidade Federal da Bahia, Salvador, 2016.

[25] MIRCHANDANI, Maya. Digital Hatred, Real Violence: Majoritarian Radicalisation and Social Media in India. Observer Research Foundation. ORF Occasional Paper 167: 2018 .

[26] www.faperj.br/?id=4062.2.1. 